\title{
Correction: Tamura, S. and Fujie, K. Material Cycle of Agriculture in Miyakojima Island: Material Flow Analysis for Sugar Cane, Pasturage and Beef Cattle. Sustainability 2014, 6, 812-835.
}

\section{Shuichi Tamura ${ }^{1, *}$ and Koichi Fujie ${ }^{2}$}

1 Graduate School of Environment and Information Sciences, Yokohama National University, Sogo-Kenkyu-Tou Room S407, 79-7 Tokiwa-dai, Hodogayaku, Yokohama-city 240-850, Japan

2 Center for Risk Management and Safety Sciences, Faculty of Environmental and Information Sciences, Yokohama National University, Sogo-Kenkyu-Tou Room S407, 79-7 Tokiwa-dai, Hodogayaku, Yokohama-city 240-850, Japan; E-Mail: fujie@ynu.ac.jp

* Author to whom correspondence should be addressed; E-Mail: tamura-shuichi-jg@ynu.ac.jp; Tel.: +81-45-339-4000; Fax: +81-45-339-4003.

Received: 18 June 2014 / Accepted: 20 June 2014 / Published: 24 June 2014

We found a typo in our previous published paper [1]. "Okinawa Main Ilsand" and "Kyushu Ilsand" are supposed be "Okinawa Main Island" and "Kyushu Island".

Figure 1. Location of Miyakojima Island.

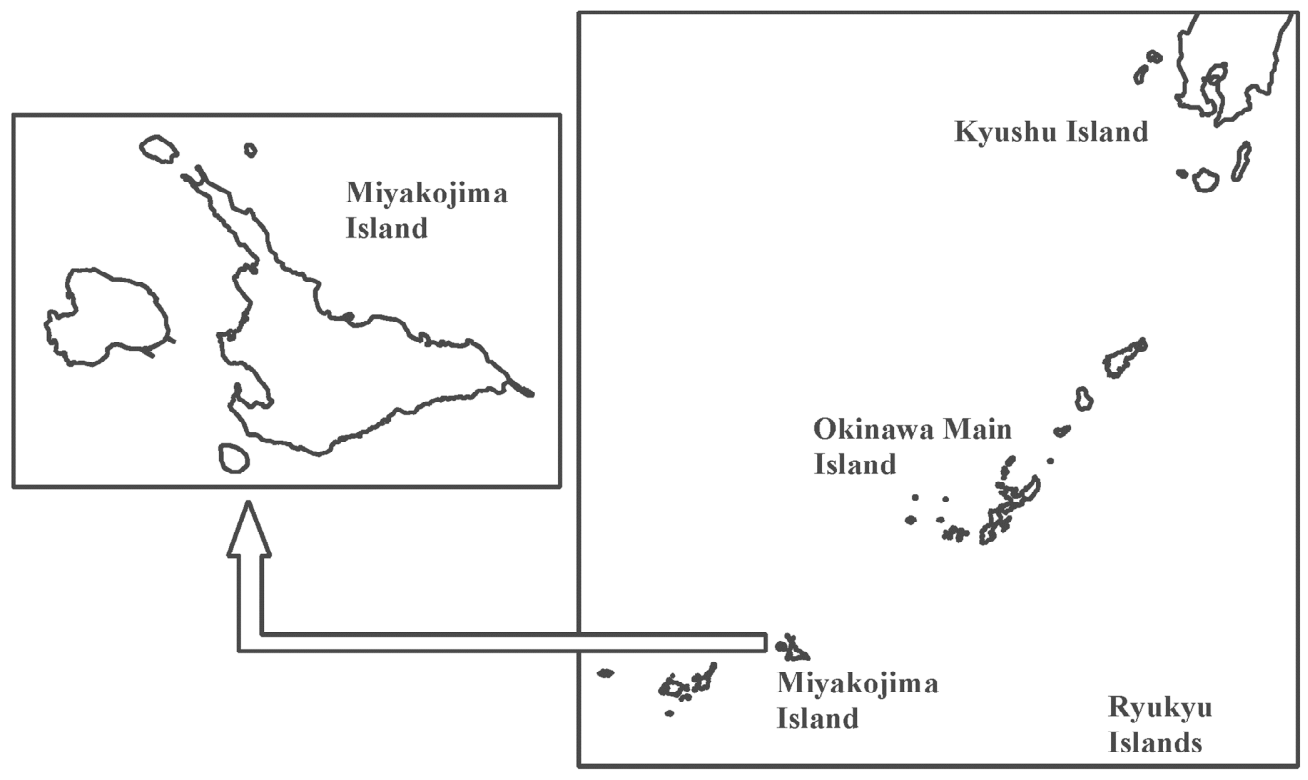


The quantity of "Dried Leave (collected by harvesters)" and "Trash" in Figure 4 is supposed to be 13,900 ton/year, not 139,000 ton/year. We apologize for any inconvenience this may have caused you.

Figure 4. MFA for Sugar Mills.

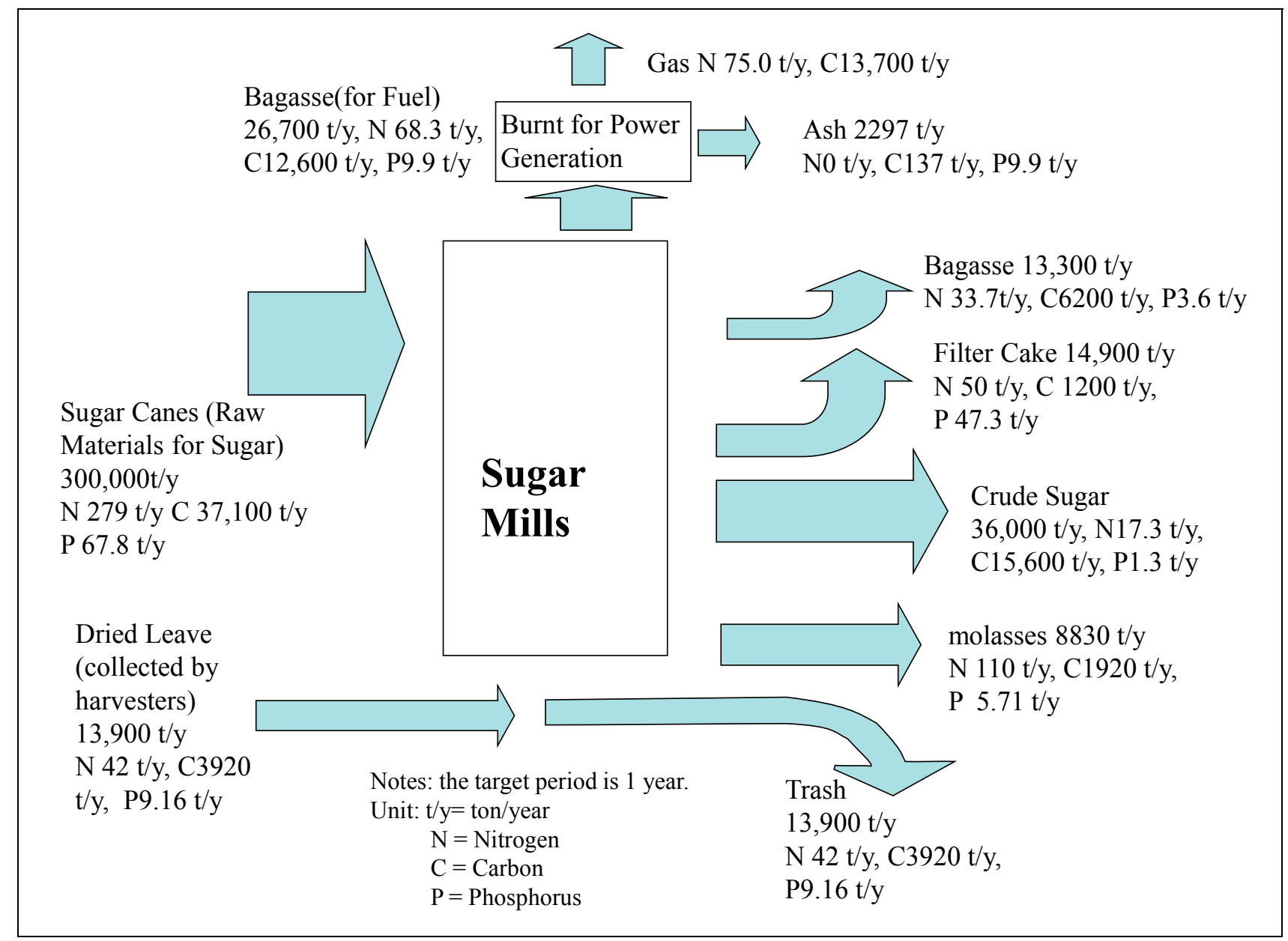

\section{Reference}

1. Tamura, S.; Fujie, K. Material Cycle of Agriculture on Miyakojima Island: Material Flow Analysis for Sugar Cane, Pasturage and Beef Cattle. Sustainability 2014, 6, 812-835.

(C) 2014 by the authors; licensee MDPI, Basel, Switzerland. This article is an open access article distributed under the terms and conditions of the Creative Commons Attribution license (http://creativecommons.org/licenses/by/3.0/). 